\section{Conclusions}

This critical evaluation of the available results of behaviour therapy must not be taken to imply that this method is of no value. In none of the groups considered was it less effective than other methods of treatment, and in the phobias it was more effective. The development of fresh symptoms was not a special hazard of behaviour therapy. It can be effective in severe chronic cases where other methods have been tried and have failed; and in some conditions-for example, rare monosymptomatic phobias-it may even be the first consideration for treatment. When individual patients are considered, behaviour therapy, like any other form of treatment, can occasionally produce startling and rapid improvements, but whether these result from enthusiasm, behaviour therapy, or other factors remains unknown.

Behaviour therapy techniques need not be seen as rivalling other therapies. Indeed, it is likely that their ultimate place will be alongside existing treatments with drugs and psychotherapy, in a particular group of neurotic disorders. At present the group which benefits most appears to consist of simple phobias (and possibly other conditions) where anxiety develops in relatively specific situations-in patients without widespread neurotic disturbance. It is suggested that the techniques should also be tried in other groups who share these characteristicspossibly in patients with social anxieties and some cases of asthma where attacks are related to specific situations. Meanwhile the experimental use of behaviour therapy should be continued, with the aim of developing new methods that will widen its range of usefulness, as, for example, the production of aversion by electric shock in transvestism and other sexual disorders. It would also be well worth while investigating its application to children's fears, such as school phobia.

\section{Summary}

Studies were made of 77 patients who received behaviour therapy in the Bethlem Royal and Maudsley Hospitals between 1956 and 1963. They were assessed and followed up for one year after treatment, together with matched control groups ( 55 patients). Assessment of symptoms was made blindly by two independent judges.

Twenty-nine severe agoraphobics did slightly but not significantly better than their 29 controls. Twelve "other phobics" -for example, animals, insects, thunder-showed far more improvement than 11 controls, this difference being significant at the end of treatment, but diminished and was no longer so after one year's follow-up. Differential response to treatment paralleled different clinical features of severe agoraphobia compared with other phobias. The latter were more continuous, much more circumscribed, with fewer other disturbances.

Results were poor in 13 patients with writer's cramp and 10 with obsessive rituals. Their corresponding controls also did poorly. Results were also poor in 13 patients with miscellaneous conditions.

It is concluded that behaviour therapy was useful in patients with circumscribed phobias, and is worth further application in other conditions in which anxiety is manifest in relatively specific situations.

The commonly reported figure of two-thirds improvement in mixed groups of neurotic patients is misleading in that it conceals marked differences in improvement rates from 0 to $100 \%$ in the course of different clinical syndromes, depending upon the timing and degree of improvement under consideration.

This work was made possible through the encouragement of Professor Sir Aubrey Lewis and a grant from the Medical Research Council. Thanks are due to Drs. H. Gwynne Jones, M. Rutter, and S. Rachman for helpful comments on the manuscript. Finally we wish to thank the psychiatrists who allowed us to follow up patients under their care, and those many general practitioners and psychologists who generously supplied us with essential information.

\section{REFERENCES}

Ajuriaguerra, J. de, Trillat, E., and Soutiran, G. (1956). Encéphale, 2,

Cooper, J. E. (1963). Lancet, 1, 411.

Eysenck, H. J. (editor) (1960). Behaviour Therapy and the Neuroses. Pergamon Press, Oxford.

Gelder, M. G., and Marks, I. M. (1965). In preparation.

Sakinofsky, I., and Wolff, H. H. (1964). Paper read to the Sixth International Congress of Psychotherapy, London. To be published.

Giel, R., Knox, R. S., and Carstairs, G. M. (1964). Brit. med. F., 2, 160.

Kihn, B. (1937). Nervenarzt, 10, 69.

Lazarus, A. A. (1963). Behav. Res. Ther., 1, 66.

Liversedge, L. A., and Sylvester, J. D. (1960). In Behaviour Therapy and the Neuroses, edited by H. J. Eysenck. Pergamon Press, Oxford.

Marks, I. M., and Gelder, M. G. (1965). Brit. F. Psychiat. In press.

Meyer, V., and Gelder, M. G. (1963). Ibid., 109, 19.

Roberts, A. H. (1964). Ibid., 110, 191.

Wolpe, J. (1958). Psychotherapy by Reciprocal Inhibition. Stanford Univ. Press, Stanford, California. (1964). Brit. f. Psychiat., 110, 28

\title{
Effect of Prolonged Carbohydrate Restriction on Serum-insulin Levels in Mild Diabetes
}

\author{
P. A. RUDNICK, $* \dagger$ M.D. ; K. W. TAYLOR,* M.A., PH.D., M.B., B.CHIR.
}

Brit. med. Э., 1965, 1, 1225-1228

The beneficial effects of carbohydrate restriction in mild diabetes have now been documented for over a century (see Bouchardat, 1875 ; Naunyn, 1906). Much more recently the glucosetolerance curve has been shown to return virtually to normal in some obese diabetics after a period of carbohydrate restriction (Newburgh and Conn, 1939; Himsworth, 1949). There are

\footnotetext{
* Department of Medicine and Diabetic Department, King's College Hospital, London.

† United States Public Health Service Research Fellow. Present address, University of California, L.A. Medical School, Los Angeles.
}

two possible mechanisms for a change of this kind. Thus tolerance might be improved because of an increased effectiveness of circulating insulin. This could be due, for example, to a lessening of insulin antagonism. Alternatively, there might be an improvement in the ability of the pancreas to secrete insulin so that more insulin was available following the stimulus due to oral glucose. This last possibility has been investigated.

Below are reported in detail the changes in the serum-insulin response to glucose during a period of carbohydrate restriction in a group of mild diabetics. The results in this group are 
compared with the insulin response to glucose of a small group of diabetics with ketosis.

\section{Methods}

Ten healthy non-obese people, aged 20-35, with no family history of diabetes served as normal subjects for measuring the serum-insulin response to glucose ingestion. Eight patients with mild diabetes were selected for the dietary studies. In these patients the diagnosis of mild diabetes had not been made more than a few days earlier, and the patients had not been placed on a diet of any kind previously. Patients were instructed to consume their normal diets for at least three days before the tests. In addition, studies were carried out on four patients who presented with marked loss of weight and ketosis, in whom insulin therapy was necessary for control.

Diet.-The overweight patients (Nos. 1-5 and 8) were given low-calorie diets in which carbohydrate restriction was marked. The two underweight patients (Nos. 6 and 7) were given diets in which carbohydrate restriction was less severe. Details of the diets are shown in Table I. Dietary instruction was given by the clinic staff, and each patient was later supervised by a trained dietitian.

Determinations.-Glucose-tolerance tests were performed before the inception of dietary treatment, and again after two and four months while the patients were on a low-carbohydrate diet. Fasting samples of venous blood were obtained and then samples at 30,60, and 120 minutes after the ingestion of $50 \mathrm{~g}$. of glucose in $25 \%$ aqueous solution. True glucose concentrations were determined in whole blood by the glucose-oxidase methods of Huggett and Nixon (1957). Blood for insulin determinations was allowed to clot at room temperature ; the serum was separated by centrifugation and then stored at $-10^{\circ} \mathrm{C}$. Insulin was assayed in serum, using the immunoassay method of Hales and Randle (1963b), employing the variant termed by them " method C." In using this method it was found desirable to carry out all measurements from one individual on the same day so as to minimize any possible variations in results. Estimates, which were carried out on undiluted serum, were done in triplicate. All stages in the procedure (apart from the actual filtration) were carried out at $4^{\circ} \mathrm{C}$. Results are expressed in terms of ox insulin standards. ${ }^{131} \mathrm{I}$ insulin of specific activity $10-80 \mathrm{mc}$. $/ \mathrm{mg}$., together with guinea-pig anti-ox insulin serum and rabbit anti-guinea-pig gammaglobulin serum ("precipitating antiserum"), was obtained commercially from the Radiochemical Centre, Amersham, Bucks.

\section{Results}

Table I shows the weight and dietary status of the eight patients treated with reduced carbohydrate intake. Patients 6 and 7 were less than their ideal weights, as computed from the data of the New York Metropolitan Life Insurance Standards. The other patients were overweight. All patients with the exception of No. 6 lost weight at the end of four months, the most substantial losses being in those who were placed on the diet lowest in carbohydrate.

\begin{tabular}{|c|c|c|c|c|c|c|c|}
\hline \multirow[b]{2}{*}{ Patient } & \multirow{2}{*}{$\begin{array}{c}\text { Age } \\
\text { and Sex }\end{array}$} & \multirow{2}{*}{$\begin{array}{c}\text { Ideal } \\
\text { Weight } \\
\text { (kg.)* }\end{array}$} & \multirow{2}{*}{$\begin{array}{l}\text { Admis- } \\
\text { sion } \\
\text { Weight } \\
\text { (kg.) }\end{array}$} & \multirow{2}{*}{$\begin{array}{l}\text { Weight } \\
4 \text { Months } \\
\text { Later } \\
\text { (kg.) }\end{array}$} & \multicolumn{3}{|c|}{ Diet in Grammes of : } \\
\hline & & & & & $\begin{array}{l}\text { Carbo- } \\
\text { hydrate }\end{array}$ & Protein & Fat \\
\hline $\begin{array}{l}1 \\
2 \\
3 \\
4 \\
5 \\
6 \\
7 \\
8\end{array}$ & $\begin{array}{ll}37 & M \\
49 & M \\
54 & M \\
60 & M \\
38 & F \\
59 & M \\
47 & M \\
62 & M\end{array}$ & $\begin{array}{l}73 \\
71 \\
77 \\
66 \\
62 \\
84 \\
77 \\
76\end{array}$ & $\begin{array}{r}153 \\
92 \\
96 \\
74 \\
72 \\
74 \\
72 \\
80\end{array}$ & $\begin{array}{r}131 \\
77 \\
86 \\
64 \\
63 \\
78 \\
68 \\
79\end{array}$ & $\begin{array}{r}90 \\
90 \\
90 \\
90 \\
120 \\
150 \\
170 \\
130\end{array}$ & $\begin{array}{l}50 \\
50 \\
50 \\
50 \\
90 \\
70 \\
90 \\
90\end{array}$ & $\begin{array}{r}50 \\
50 \\
50 \\
50 \\
130 \\
90 \\
140 \\
120\end{array}$ \\
\hline
\end{tabular}

* New York Metropolitan Life Insurance Co. Statistical Bulletin, NovemberDecember 1959.
Table II shows the blood-glucose and serum-insulin responses to oral glucose of these patients and the 10 normal people to glucose-tolerance tests. Serum-insulin responses in normal people are very similar to those already reported by Hales and Randle (1963b) for this method. In the diabetic group patients $1-5$, who were overweight at the outset, markedly improved their glucose tolerance after two months of diet. Much less improvement took place in the next two months. These results are shown in summary in the Chart, which depicts the mean glucose-tolerance curves in these five patients, before and during the period of diet. Furthermore, the improvement in glucose tolerance appears to be paralleled by an increased response of serum insulin to glucose. Similar results are seen in patients 6 and 7, who were underweight at admission.

The overall serum-insulin levels for these patients are also given in Table II. By comparison with normal people the

TABLE II.-Serum-insulin and Blood-glucose Levels, After Oral Glucose,

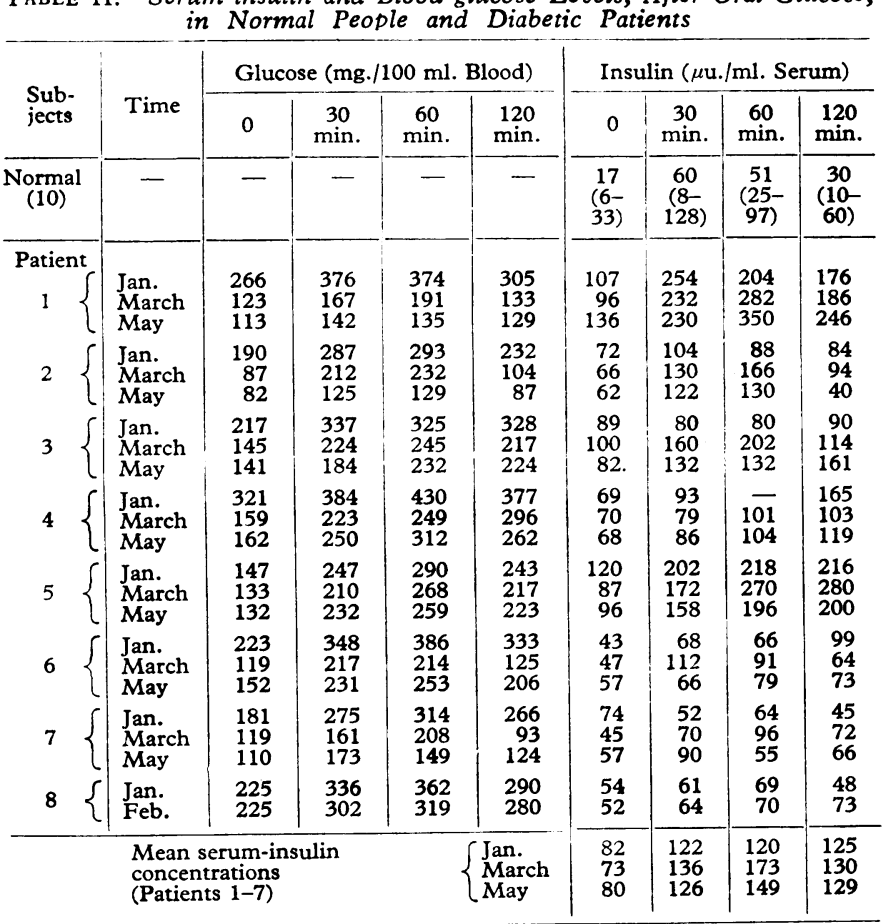

For normals, results are expressed as means and ranges.

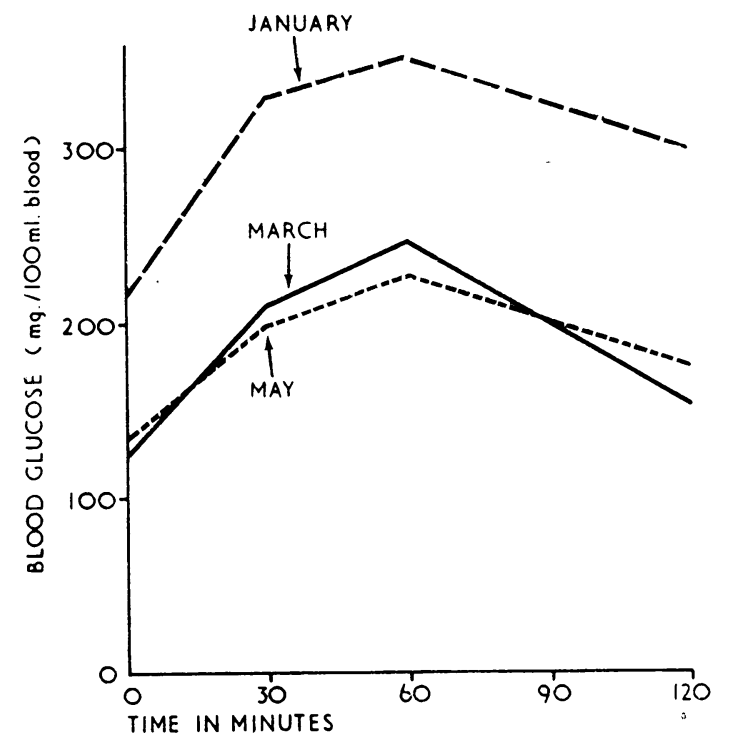

Mean blood-glucose concentration after $50 \mathrm{~g}$. of oral glucose in seven mild diabetics during carbohydrate restriction. For further details, see text. 
absolute levels are very much higher both in the fasting state and after glucose. It is also clear from the summary of the data for the seven patients that the level of serum insulin is considerably increased after glucose following two and four months of the dietary treatment. This is apparent both at 30 and at 120 minutes after glucose, but especially 60 minutes after sugar ingestion. The maximal increases in serum insulin took place two months after the start of treatment, and in some instances there seems to have been a falling off in responsiveness to glucose during the last two months. Nevertheless, seruminsulin levels are still in excess of the pretreatment levels at this time. The increased level of serum insulin following glucose, which appears to be a consequence of the diet, is better shown in Table III, where serum-insulin values are expressed as differences between the fasting levels and those obtained at 60 minutes after glucose for the six patients on whom data were available before treatment. Despite the wide range in values, the differences in responsiveness between January and March is significant $(0.05>\mathrm{P}>0.02)$.

TABLE III.-Effect of $50 \mathrm{~g}$. of Oral Glucose on Serum-Insulin Values $(\mu u . / m l$.$) in Six Diabetic Patients Who Showed a Clinical Response$ to Diet

\begin{tabular}{c|c|c}
\hline January & March & May \\
\hline $36 \pm 20 \cdot 2$ & $111 \pm 25 \cdot 2$ & $75 \pm 31 \cdot 3$ \\
\hline
\end{tabular}

Results are expressed as differences \pm S.E. of differences between serum levels in the fasting state and after glucose. For January-March, $0.05>\mathrm{P}>0.02$.

Results on patient 8 are of considerable interest. Although he adhered to his diet, his symptoms of diabetes and heavy glycosuria persisted. He therefore had to be excluded from the study after three weeks. The results for this patient (Table II) indicate an inability to respond to hyperglycaemia.

Table IV shows blood-glucose and serum-insulin values derived from four patients presenting with severe diabetes, accompanied by rapid loss of weight and by ketosis. All these patients needed to be treated with insulin. One week after admission a morning dose of soluble insulin was delayed, $50 \mathrm{~g}$. of glucose was given, and serum-insulin levels were determined. The serum-insulin response to glucose indicates that a rising blood sugar failed to stimulate the islet tissue to further insulin output.

TABLE IV.-Serum-insulin and Blood-glucose Concentrations, Fasting and 60 Minutes After $50 \mathrm{~g}$. of Oral Glucose, in Four Severe Diabetics

\begin{tabular}{|c|c|c|c|c|c|c|}
\hline \multirow{2}{*}{ Patient } & \multicolumn{3}{|c|}{ Blood Glucose (mg./100 ml.) } & \multicolumn{3}{|c|}{ Serum Insulin ( $\mu \mathrm{u} . / \mathrm{ml})}$. \\
\hline & Admission & $0 \mathrm{~min}$. & $60 \mathrm{~min}$. & Admission & $0 \mathrm{~min}$. & $60 \mathrm{~min}$. \\
\hline $\begin{array}{l}1 \\
2 \\
3 \\
4\end{array}$ & $\frac{354}{\frac{}{275}}$ & $\begin{array}{l}307 \\
185 \\
130 \\
199\end{array}$ & $\begin{array}{l}375 \\
289 \\
298 \\
366\end{array}$ & $\frac{21}{9}$ & $\begin{array}{l}45 \\
95 \\
59 \\
47\end{array}$ & $\begin{array}{l}36 \\
73 \\
91 \\
56\end{array}$ \\
\hline
\end{tabular}

\section{Discussion}

These experiments once again demonstrate that the two broad classes of diabetics-the mild obese type and the thin type liable to ketosis-differ in their capacity to secrete insulin (Bornstein and Lawrence, 1951 ; Vallance-Owen et al., 1955 ; Seltzer and Smith, 1959 ; Berson and Yalow, 1961 ; Taylor, 1963 ; Hales and Randle, 1963a). Thus, as expected, patients who presented with ketosis and loss of weight were unable to secrete any extra insulin in response to glucose (Table IV). Patients with mild diabetes, controlled by diet, showed, however, a rapid and sustained rise in serum insulin after glucose (Table II), although the rise appeared to be delayed in comparison with results derived from normal people. Patient 8 , who showed no rise in serum insulin after glucose, behaved in a manner which was similar to that of the group of ketotic patients, although this patient exhibited no ketosis. It must be assumed that his insulin reserves were exhausted at the outset of the study.
The absolute values of serum insulin are very much greater than those encountered during glucose-tolerance tests in normal people. This is well seen from an examination of the fasting values for serum insulin, which remained at approximately four times those seen in the normal group, and did not change significantly at any period during the course of the treatment. High fasting values for blood insulin have also been reported both in early human diabetes and in pre-diabetes by other workers using a variety of methods of insulin assay (VallanceOwen et al., 1955 ; Phear, 1962 ; Steinke et al., 1963 ; Hales, 1964). Since the fasting blood-glucose levels are raised, it might be supposed that these themselves would increase the secretion of insulin. Such elevated levels of blood glucose might be due either to the presence of insulin antagonists of the albumin type (Ensinck and Vallance-Owen, 1963) or to the antagonism that may be associated with deranged fatty-acid metabolism (Randle et al., 1963). Nevertheless, three patients (Nos. 1, 2, and 7) had high blood-insulin levels despite fasting bloodglucose concentrations which were near or in the normal range after treatment. It may be the case that other factors, such as elevated serum-ketone levels are partly responsible for the high fasting levels of serum insulin. There is now evidence to suggest that ketone bodies may possess a direct stimulatory effect on the cells of the pancreas, so as to increase the secretion of insulin (Madison et al., 1963). Considerably elevated levels of ketone bodies may be present in the blood of untreated mild diabetics, even in the absence of ketonuria (Berry, Williamson, Pyke, and Taylor, unpublished observations), and these might contribute to the rise in blood insulin, particularly in the fasting state.

An important general inference from these results is that the islet tissue of these mild diabetics is capable of a normal qualitative response to sugars. If destruction of the islet tissue has not been complete, improvement in islet-cell function is possible. The results given in Tables II and III show that such an improvement has in fact taken place. After a period of carbohydrate restriction there is a rise in serum-insulin levels following glucose which is coincident with the improvement in glucose tolerance. In some instances tolerance appears to be returned virtually to normal. This is especially the case two months after treatment (see Table III), though it is also evident four months after dieting. The reason for any change in the responsiveness of the pancreas during the last two months of treatment is not known.

In these studies, the rise in serum-insulin levels could be due either to an increased secretion of insulin or to its lessened destruction. There is at present, however, little evidence for an increased breakdown of insulin in diabetes (see Berson et al., 1956). We would conclude that after two months of fasting there is an improved ability to secrete insulin in response to glucose.

At first sight it might be thought that these results conflict with those obtained by Hales and Randle (1963a) for bloodinsulin response to glucose of normal people who were subjected to a short period of dietary restriction of carbohydrate. In these subjects five days on a low-carbohydrate diet greatly impaired glucose tolerance. However, Himsworth (1949) has been careful to point out that there is a marked contrast in the response of normal people as opposed to mild diabetics to effects of carbohydrate restriction. Tolerance is improved by a low-carbohydrate diet in mild diabetics, though it is impaired in normal people. Hales and Randle (1963a) have explained the effects of carbohydrate restriction in normal people by proposing that increased levels of circulating non-esterified fatty acids (or intracellular changes in fat metabolism) are responsible for the antagonism to insulin which accompanies this condition. Similar explanations for carbohydrate intolerance during starvation have also been proposed by Schalch and Kipnis (1964). While events of this kind appear to offer an explanation for the changes in insulin sensitivity which accompany starvation in normal people, it does not seem likely that a diminished 
degree of insulin antagonism is responsible for the improvement in tolerance after carbohydrate restriction in this group of diabetics. If antagonism to insulin had lessened then the levels of fasting insulin, as well as the levels after glucose, might have been expected to decline.

A possible explanation for these effects is that the lowering of blood glucose which follows dietary restriction may have allowed an improvement in the function of the beta cells. The studies of Dohan and Lukens (1948) have demonstrated the role of hyperglycaemia in causing islet-cell deterioration. Seltzer and Harris (1964) have also studied the effects of prolonged glucose infusion on blood insulin in normal people and diabetic patients. They have demonstrated the ease with which the insulin-secretory mechanism becomes exhausted in mild diabetics, when the islet cells are subjected to high bloodglucose levels for long periods of time. It is suggested that in the experiments reported in this paper the converse may have taken place, and that the lowering of blood glucose by diet has improved the ability of the pancreas to secrete insulin, which in turn has resulted in the improvement of glucose tolerance. Very occasionally similar remissions may follow treatment of severe diabetes with insulin (Taylor, 1960), and again one of the factors which make possible this type of improvement may be an increased secretion of insulin.

Weight reduction alone may not be the most important factor in the changes described in these obese patients. It will be seen from Table II that glucose tolerance and the bloodinsulin response to glucose also improved in patients 6 to 7 , neither of whom underwent significant weight reduction during the study. Moreover, the insulin response to glucose may also be improved after sulphonylurea therapy (Phear, 1962), suggesting that loss of weight is not an obligatory factor in the improvement.

Finally, these experiments give some support to the idea, particularly emphasized by Joslin et al. (1959), that energetic attempts to lower blood sugar are of cardinal importance in the early treatment of diabetes to prevent irreversible damage to islet cells.

\section{Summary}

Serial studies of the response of serum insulin to glucose ingestion have been made during a four-month period in a group of diabetic patients thought likely to respond to dietary restriction of carbohydrate.
In seven such patients, whose glucose tolerance improved on the diet, serum-insulin levels following glucose were higher after the diet, despite lower blood-glucose levels. Fasting serum-insulin levels were much higher in the diabetic group than in normal people and were unchanged after treatment.

It is suggested that these results are due to an improvement in the capacity of the pancreas to secrete insulin which follows the lowering of blood-glucose levels by dietary management.

We are indebted to Dr. Wilfrid Oakley and Dr. David Pyke, of the Diabetic Department, King's College Hospital, as well as to the hospital dietitians for many useful discussions and much valuable advice about the patients. We would also like to thank Dr. Clifford Hoyle for general help and encouragement, and $\mathrm{Mr}$. D. G. Parry and Miss Marjorie Sandiford, who helped us at various times with the study.

This work was supported by grants from the Medical Research Council (to K. W. T.) and also by the British Diabetic Association and British Insulin Manufacturer. P. A. R. gratefully acknowledges support from a U.S. Public Health Service grant (1-F2-AH19,337-01).

\section{REFERENCES}

Berson, S. A., and Yalow, R. S. (1961). Amer. F. Med., 31, 874. Bauman, A., Rothschild, M. A., and Newerly, K. (1956). 7. clin Invest., 35, 170

Bornstein, J., and Lawrence, R. D. (1951). Brit. med. F., 1, 732.

Bouchardat, A. (1875). De la Glycosurie ou Diabète Sucre. GermerBaillière, Paris.

Dohan, F. C., and Lukens, F. D. W. (1948). Endocrinology, 42, 244.

Ensinck, J., and Vallance-Owen, J. (1963). Diabetes, 12, 353.

Hales, C. N.. (1964). Ciba Fdn Colloq. Endocr., 15, 140.

Hales, C. N. (1964). Ciba Fdn Colloq. Endocr.,

—_ and Randle, P. J. (1963a). Lancet, 1,

Himsworth, H. P. (1949). Lancet, 1, 465.

Huggett, A. St. G., and Nixon, D. A. (1957). Ibid., 2, 368

Joslin, E. P., Root, H. F., White, P., and Marble, A. (1959). The Treat ment of Diabetes Mellitus, 10th ed. Kimpton, London.

Madison, L. L., Mebane, D., and Lochner, A. (1963). F. clin. Invest. 42, 955 .

Naunyn, B. (1906). Diabetes Mellitus, 2nd ed. Holder, Vienna.

Newburg. (1939). 7. Amer. med. Ass., 112, 7

Phear, D. N. (1962). Lancet, $2,955$.

Phear, D. N. (1962). Lancet, 955. . N and Newsholme, A. E. (1963). Ibid., 1, 785 .

Ibid., 1, 'S., and Kipnis, D. M. (1964). F. clin. Invest., 43, 1283.

Seltzer, H. S., and Harris, V. L. (1964). Diabetes, 13, 6.

and Smith, W. L. (1959). Ibid., 8, 417.

Steinke, J., Soeldner, J. S., Camerini-Dávalos, R. A., and Renold, A. E. (1963). Ibid., 12, 502 .

Taylor, K. W. (1960). Brit. med. F., 1, 1853.

(1963). Ibid., 1, 511.

Vallance-Owen, J., Hurlock, B., and Please, N. W. (1955). Lancet, 2, 583.

\title{
Myxoedema After Deep $X$-ray Therapy to the Neck
}

\author{
J. L. MARKSON,* F.R.C.P.ED., F.R.C.P.GLASG. ; G. E. FLATMAN, $\dagger$ M.D., F.R.C.S., F.F.R.
}

Brit. med. F., 1965, 1. 1228-1230

External irradiation of the thyroid gland was at one time the standard treatment for thyrotoxicosis, and Groover et al. (1929) reported the incidence of severe hypothyroidism after radiotherapy to be $1.3 \%$ in a series of 305 cases. After treatment with radioiodine this complication is frequent, and was found by Green and Wilson (1964) to be $29 \%$ over a follow-up period of 10 years. They related its occurrence to the dose of radiation relative to the size of the gland, and not to an autoimmune

* Consultant Physician, Stobhill General Hospital, Glasgow.

+ Consultant Radiotherapist, Western Infirmary and Stobhill General Hospital, Glasgow. reaction. As a complication of deep $x$-ray therapy to the neck in non-thyrotoxic patients, however, hypothyroidism would seem to be very rare, and we have been able to trace only one case in the literature, in which it appeared six years after treatment of carcinoma of the larynx (Félix et al., 1961). We have recently encountered five patients who developed myxoedema after irradiation of the neck for reticuloses involving cervical lymph nodes, and for carcinoma of breast, oesophagus, and nasopharynx respectively. These cases are reported because of the rarity of this complication, and because of the interesting findings of thyroid auto-antibodies in all. 